\title{
Medicaid Work Requirements: the Need for Local Advocacy
}

\author{
Nathan T. Douthit, MD
}

Brookwood Baptist Health Medical Education, Birmingham, AL, USA.

J Gen Intern Med 34(2):169-70

DOI: $10.1007 /$ s11606-018-4743-9

(C) Society of General Internal Medicine 2018

\section{INTRODUCTION}

Early in her tenure as the Administrator of the Centers for Medicaid and Medicare Services (CMS), Seema Verma began mentioning work requirements as a potential addition to Medicaid eligibility. Support or lack thereof for this idea seems largely to fall on partisan lines. ${ }^{1}$ Nonetheless, this idea has quickly gained momentum. Recently, work requirement waivers have been approved for Indiana, New Hampshire, Arkansas, and Kentucky, although Kentucky's approval was revoked following legal challenges. Further requests from Arizona, Kansas, Maine, Mississippi, Ohio, South Dakota, Utah, and Wisconsin are still pending. A further six states, South Carolina, Louisiana, Virginia, Alabama, Alaska, and Minnesota, have also expressed interest in pursuing the required waivers. Of the 19 states who have not adopted Medicaid expansion, nine-UT, VA, KS, MS, WI, SD, SC, ME, and $\mathrm{AL}$ - have either applied for or are actively considering applying for these waivers. ${ }^{2}$

While multiple professional organizations express opposition to work requirements, including a resolution from the American Medical Association and the joint principles from the American Academy of Family Physicians, American Academy of Pediatrics, The American College of Obstetricians and Gynecologists, The American College of Physicians, the American Osteopathic Association, and the American Psychiatric Association, it is surprising that the waiver applications continue to gain steam. It may be theorized that the statements by these national organizations lack power; even though these waivers are granted by the federal government, states are the ones who initiate and pursue this process. This paper presents a brief history of work requirements, the problems presented by work requirements, and what physicians can do on a local level to advocate for their patients.

Received September 21, 2018

Revised November 2, 2018

Accepted November 8, 2018

Published online December 10, 2018

\section{A BRIEF HISTORY OF MEDICAID WORK REQUIREMENTS}

Work requirements are added to Medicaid through Section 1115 of the Social Security Act, which was enacted to allow experimentation in federal welfare programs. Section 1115 was amended to cover Medicaid when it was adopted by Congress in 1965. Although intended to be small-scale, controlled experiments, Section 1115 is now a central part of many state Medicaid programs which, "allow for comprehensive, statewide adjustments to eligibility, benefits, cost-sharing, and payment rates." All that is required for these waivers to be approved is explain how they would "assist in promoting [Medicaid's] objectives." These objectives include providing "medical assistance" to those "whose income and resources are insufficient to meet the costs of necessary medical services." 3 The approval of work requirements for Medicaid under Section 1115 is a break from prior administrations' rulings, as both Republican and Democratic administrations previously found work requirements to be unhelpful in promoting Medicaid's goals. The current administration seems to have taken a special interest in work requirements, "including fast-track approvals and longer demonstration approval periods."

\section{THE PROBLEMS WITH WORK REQUIREMENTS} \section{The Problem Is Not As Widespread As Believed}

There is a very small target group for these requirements. ${ }^{4}$ According to the Kaiser Family Foundation, 60\% of nonelderly Medicaid recipients are working full or part time and $80 \%$ are part of working families. Of those who do not work, $35 \%$ are disabled or chronically ill, $28 \%$ are caretakers for family members, $18 \%$ are students, $8 \%$ are actively seeking work, and $8 \%$ are retired. This leaves about $3 \%$ of the adult Medicaid population not currently working who may be "choosing" unemployment. ${ }^{4}$ Indiana, which has expanded Medicaid, estimates that $70 \%$ of enrollees would not be subject to their work requirements; Maine, which has not expanded Medicaid, estimates that only about $7 \%$ of enrollees would be subject to the requirement, "before taking into account those who would qualify for exemptions such as being physically or mentally unable to work." 4 


\section{The Administrative Burden Would Be Significantly Costly}

The complexity of adjudicating who is "able-bodied," who is a "caretaker," and who is involved in "productive community engagement" is likely to cause significant cost, delay, and bureaucratic burden to the Medicaid program. This will also likely cause eligible individuals to be removed from the program due to confusion, error, and lack of education. Special cases like unexpected unemployment must also be considered, as most who are unemployed and can work are actively looking for work. Also, the amount of money spent for TANF enrollees who were required to work, which some see as too low, is far more than currently budgeted in Medicaid state work requirements. The administrative cost remains to be seen in total, but may end up costing states more money than the savings accrued by removing non-employed able-bodied adults from the rolls. ${ }^{4}$

\section{The Effects on Patients May Not Produce Health}

The work requirement requests are now being approved in order to "test the hypothesis that requiring work or community engagement ... will result in more beneficiaries being employed or engaging other productive community engagement, thus producing improved health and well-being." ${ }^{33}$ This is based on the theory that unemployment is bad for health. Indeed, there is a strong correlation between unemployment and poor health, but it is by no means apparent whether poor health causes unemployment or is the result of it. TANF has instituted work requirements, and many studies have found that even if these increase employment, they do not reduce poverty. ${ }^{4}$

The barriers to work not addressed by work requirements include physical and mental health conditions, addiction, limited education, criminal histories, lack of affordable childcare, and many others. Many of these issues are ameliorated by having healthcare, making it easier for patients to work. In Ohio, over half of working Medicaid enrollees said that having Medicaid made it easier for them to continue working. In Michigan, $69 \%$ stated they performed better at work following Medicaid expansion giving them coverage, and over half of the unemployed Medicaid expansion enrollees said coverage made them better able to look for work. ${ }^{4}$

\section{HEALTHCARE PROFESSIONALS AS LOCAL ADVOCATES}

Healthcare professionals are natural patient advocates. They see the effects on the ground that may be missed by politicians and bureaucrats. It may be that work is beneficial for some patients' health, and that Medicaid can help incentivize the certain unemployed persons to look for employment. However, this has not been definitively proven and the wholesale removal of insurance from vulnerable populations coupled with the political barriers to access may prove devastating to Medicaid's objectives. Early analysis seems to indicate wide differences between Democratic and Republican support. "Taken together, stark differences across political parties could translate into major changes in the design of Medicaid programs across the country, depending on the balance of power within each state's branches of government. As states pursue and implement changes to Medicaid policy, there is a critical need to evaluate the impact on access to care and health outcomes for the Medicaid population." ${ }^{1}$ As in any medical therapy, the burden of proof lies on those who wish to intervene. Despite the national organizations mentioned above opposing these measures, the true power for advocacy is going to lie in state and local governments.

A good first step in opposition to these requirements is contacting state legislatures through local representatives. The attitudes of state legislators toward work requirements have been described in the literature. ${ }^{1}$ This level of advocacy can be easily accomplished through websites such as https:// openstates.org/find your_legislator/. Next, those who feel strongly about this issue can write op-eds in local media outlets in order to inform the population about the stories of patients who will be profoundly impacted by these new requirements. Assistance with this can be achieved through organizations like The Op-Ed Project (https://www.theopedproject.org/). Finally, county and state medical organizations can make their views known to legislators through testimony and resolution. In Minnesota, "more than 125 Minnesota groups stand firmly opposed, including counties, doctors, nurses, mental health providers, disability advocates, addiction specialists, hospitals, nonprofits and other health care organizations." Municipal, county, and state medical societies have an important role to play in this level of local advocacy. This is an urgent and important patient care issue. With a relatively small amount of effort, healthcare professionals can take the lead in insuring that vulnerable patients are cared for in years to come.

Corresponding Author: Nathan T. Douthit, MD; Brookwood Baptist Health Medical Education, Birmingham, AL, USA (e-mail: Nathan. Douthit@bhsala.com).

\section{Compliance with Ethical Standards:}

Conflict of Interest: The author declares that he does not have a conflict of interest.

\section{REFERENCES}

1. Zhu JM, Chhabra M, Grande D. Concise research report: the future of Medicaid: state legislator views on policy waivers. J Gen Int Med. 2018;1-3

2. Kaiser Family Foundation. Medicaid Waiver Tracker: Which States have Approved and Pending Section 1115 Medicaid Waivers? [internet] KFF. 2018. Obtained on 26 October 2018 from https://www.kff.org/medicaid/ issue-brief/which-states-have-approved-and-pending-section-1115-medicaid-waivers/

3. Bagley $\mathbf{N}$. Are Medicaid Work Requirements Legal?. JAMA. 2018;319(8):763-4.

4. Musumeci M, Zur J. Medicaid Enrollees and Work Requirements: Lessons from the TANF Experience. Kaiser Family Foundation. 2017.

5. Carlson A, Berglin L. Medicaid Work Requirements: Proposal sounds appealing, but is far from it [internet]. Star Tribune. Minnesota; 2018. Obtained on 26 October 2018 from http://www.startribune.com/medicaid-work-requirements-proposal-sounds-appealing-but-is-far-from-it/ $481114581 /$ 